\title{
PAINEL DE GESTÃO ACADÊMICA DOS CURSOS DE GRADUAÇÃO DO INSTITUTO FEDERAL DE EDUCAÇÃO, CIÊNCIA E TECNOLOGIA DE SERGIPE: UMA PROPOSTA DE POWER BIß COMO FERRAMENTA GERENCIAL
}

http://dx.doi.org/10.5902/2318133864035

\author{
Baby de Fátima Barbosa Parisi ${ }^{1}$ \\ Kleber Fernandes de Oliveira²
}

\begin{abstract}
Resumo
Neste texto apresenta-se um relato da elaboração de um painel de gestão acadêmica, utilizando o Power $\mathrm{B} \mid \AA$ como ferramenta facilitadora de controle, monitoramento e análise dos dados no Instituto Federal de Educação, Ciência e Tecnologia de Sergipe. O objetivo foi mostrar como o sistema pode auxiliar na tomada de decisão dos gestores, além de permitir a eficiência na transparência ativa e mitigar os gargalos no acesso e gerenciamento dos dados já disponíveis. Percebeu-se que o uso do Power $\mathrm{BI} \cap$ mostrou-se uma solução eficiente para a problemática apresentada, pois, possibilita análises flexíveis, intuitivas e rápidas, apresentando, de maneira dinâmica e ágil, um panorama sobre as principais dimensões estratégicas do ensino.

Palavras-chave: Power $\mathrm{BI}$; ; gestão do conhecimento; ensino superior; business intelligence; transparência ativa.

\section{ACADEMIC MANAGEMENT PANEL OF GRADUATION COURSES OF THE FEDERAL INSTITUTE OF EDUCATION, SCIENCE AND TECHNOLOGY OF SERGIPE: A PROPOSAL OF POWER BIß AS A MANAGEMENT TOOL}

\section{Abstract}

The research is an account of the construction of an academic management panel, using Power $\mathrm{BI} B$ as a tool to facilitate data control, monitoring and analysis at the Federal Institute of Education, Science and Technology of Sergipe. The objective is, therefore, to show how the system can assist managers in making decisions, in addition to allowing efficiency in active transparency and also mitigating the bottlenecks in accessing and managing the data already available. As a result of this investigation, it was possible to demonstrate that the use of Power $B \mid \Theta$ proved to be an efficient solution to the presented problem, since it allows flexible, intuitive and quick analysis, presenting in a dynamic and agile way, an overview of the main strategic dimensions of teaching.

Key-words: Power $\mathrm{BI}$; ; knowledge management; university education; business intelligence; active transparency.

\footnotetext{
1 Universidade Federal de Sergipe, Brasil. E-mail: fatimaparisi@gmail.com.

2 Universidade Federal de Sergipe, Brasil. E-mail: koliveira@academico.ufs.br.
} 


\section{Introdução}

a administração pública busca-se a gestão do conhecimento. Enquanto nas empresas privadas a gestão do conhecimento é usada, por exemplo, para acumulação de riquezas, aumento dos lucros e concentração de capital intelectual, nas organizações públicas a gestão do conhecimento é utilizada para potencializar o exercício da cidadania, bem coletivo, transparência e a eficácia no uso dos recursos públicos (Mendes, 2005). À medida em que as organizações públicas são transformadas em instituições com foco no conhecimento, este passa a ser a sua marca principal na escolha e formatação das políticas públicas (Batista, 2012).

Criar uma cultura na qual o conhecimento seja valorizado e compartilhado é um dos maiores desafios na prática da administração pública. Há, no entanto, um outro também importante: o de reformar a percepção reducionista de que conhecimento é poder e, em seu lugar, cultivar o compartilhamento como princípio da inteligência institucional (Angelis, 2013).

Tão latente quanto a gestão do conhecimento no setor público é a transparência das ações e informações. O acesso à informação na administração pública deve ser notabilizado como um direito fundamental e inerente ao cidadão (Piaia et al, 2017). Sua dilatação possibilita o conhecimento e amplifica as formas de participação política, estimulando a comunicação entre a sociedade e o poder público. Com a informação disponível é possível permitir que o indivíduo acompanhe, fiscalize e cobre ações e decisões do gestores públicos, possibilitando uma gestão transparente, eficiente e justa (Vesoloski; Vesoloski; Dezordi, 2020).

Estudos do TCE/CE (2017) apontam que a transparência é muito mais do que publicidade. Publicidade trata da divulgação dos atos administrativos nos meios de informação oficiais, atendendo o requisito formal de validade e eficácia destes atos. Já a transparência é uma atitude permanente, um empenho efetivo de comunicar, por quaisquer meios disponíveis, as ações e os resultados do órgão público aos usuários internos e externos.

Muitas informações disponibilizadas em websites gerenciados por entes públicos estão indisponíveis, incompletas e até incompreensíveis (Melo; Fuchigami, 2019). Para Silva, Hoch e Righi (2013) a tecnologia não é a única responsável para que se tenha resultados positivos quando se trata de divulgação da informação. Além dela é necessário que a administração pública garanta 0 acesso aos dados e reconheça a legitimidade do direito do cidadão de entender e acompanhar tudo que está sendo feito pela gestão pública (Vesoloski; Vesoloski; Dezordi, 2020).

Produzir e consentir o acesso da sociedade à informação simples, atualizada e compreensível é fundamental para o exercício da transparência. Esse é o primeiro passo para que os cidadãos possam participar e exercer o controle sobre a gestão pública. Portanto, a gestão do conhecimento, a transparência e o gerenciamento da informação pode tornar a administração pública mais eficiente, democrática e atuante.

As ferramentas de Business Intelligence - BI ou Inteligência de Negócios - podem ser importantes na análise e na tomada de decisão no setor público, especialmente na área educacional. Com a finalidade de uso consciente e estratégico das informações o $\mathrm{BI}$ auxilia na coleta, organização, análise, compartilhamento e controle dos dados como parte fundamental deste trabalho (Lapa; Bernardino; Figueiredo, 2014). 


\section{Fundamentação teórica}

Para se tomar uma decisão é necessário analisar informações e convertê-las em ações (Oliveira, 2004). O processo decisório numa organização, seja pública ou privada, requer técnicas de planejamento, organização, direção e controle (Paludo, 2010). O mesmo autor evidencia que no caso de entes públicos, por terem o objetivo comum de atendimento das necessidades do cidadão, sua estrutura maior e mais complexa, contribui para diminuição da autonomia de suas ações, o que influencia diretamente o seu poder e forma de decisão.

O setor privado, entretanto, não é o mundo ideal à prova de erros e que deva ser seguido sem que haja reflexão e questionamentos a seu respeito. Há uma forte idealização que a iniciativa privada seria mais eficiente, no sentido de trabalho, desenvolvimento e qualidade, sempre que comparada ao serviço público (Fenae, 2019). As críticas recorrentes de que o setor público é lento e burocrático são mais presentes nos países em que ele é marginalizado e obrigado a desempenhar um papel puramente administrativo (Mazzucato, 2014). O sucesso de uma organização, seja ela pública ou privada, é também resultado do grau de envolvimento da gestão. Enquanto as empresas privadas visam lucro financeiro, as públicas são orientadas pelo interesse coletivo e essa diferença é suficiente para que as comparações devam ser comedidas e proporcionais (Mazzucato, 2014).

Importância do conhecimento no processo decisório

O processo decisório está presente no cotidiano das instituições, pois, de acordo com Sobral e Peci (2008), a decisão pode ser compreendida como uma escolha a ser feita entre alternativas ou opções e tem como intuito resolver algum problema ou fazer proveito de alguma oportunidade. Para realizar uma escolha diante de tantas opções disponíveis é necessária a análise dos riscos e dos efeitos que resultam dessa tal escolha. Os mesmos autores dizem que cada momento de decisão pode ser organizado com alternativas ranqueadas numa escala que varia entre a completa certeza à total incerteza, conforme for 0 detalhamento das informações sobre cada opção e seus respectivos resultados.

No processo decisório um dos elementos fundamentais é a informação, mas para que ela exista são necessários dados, que são partes isoladas da informação. Estes dados, se analisados sozinhos, não são expressivos, ou seja, não são informações (Loh, 2014). No momento em que há dois ou mais dados e juntos eles têm algum significado, eles se transformam em informação.

De acordo com Loh (2014) a tecnologia armazena dados e as pessoas trabalham com informações. A partir disto depreende-se que no contexto organizacional as informações são imprescindíveis diante da necessidade de escolher alguma alternativa em detrimento de outra. Pela figura 1 é possível visualizar essas condições que influenciam no processo decisório. 
Figura 1 -

Condições de decisão.

TOTAL INCERTEZA

Não há informação suficiente para que o indivíduo relacione as probabilidades aos resultados

possíveis.

\section{COMPLETA CERTEZA}

Informações concatenadas diretamente as suas consequências.

\begin{tabular}{c|cc}
\multicolumn{1}{c|}{ SEM } & \multicolumn{1}{c|}{ INCERTEZA } & INFORMAÇÃO \\
INFORMAÇÃO & $\begin{array}{l}\text { Há informações disponíveis sobre as } \\
\text { alternativas, mas elas não são } \\
\text { satisfatórias para prever a } \\
\text { possibilidade de situações } \\
\text { específicas. }\end{array}$ & COMPLETA \\
Fonte: Sobral e Peci (2008) & &
\end{tabular}

Fonte: Sobral e Peci (2008).

INFORMAÇÃO

PARCIAL

Apesar desta análise algumas organizações públicas ainda não se conscientizaram da importância dos seus dados pois eles, na maioria das vezes, ainda são utilizados apenas como registro e histórico. Dados podem se tornar informações úteis, que são utilizadas como elemento básico nas decisões estratégicas e devem ser tratadas como matéria-prima para compor a gestão do conhecimento. A pirâmide do conhecimento mostra que a partir dos dados têm-se informações, com elas é gerado conhecimento e a partir deste arranjo nasce a sabedoria (Ackoff, 1989).

Figura 2 -

Pirâmide do conhecimento.

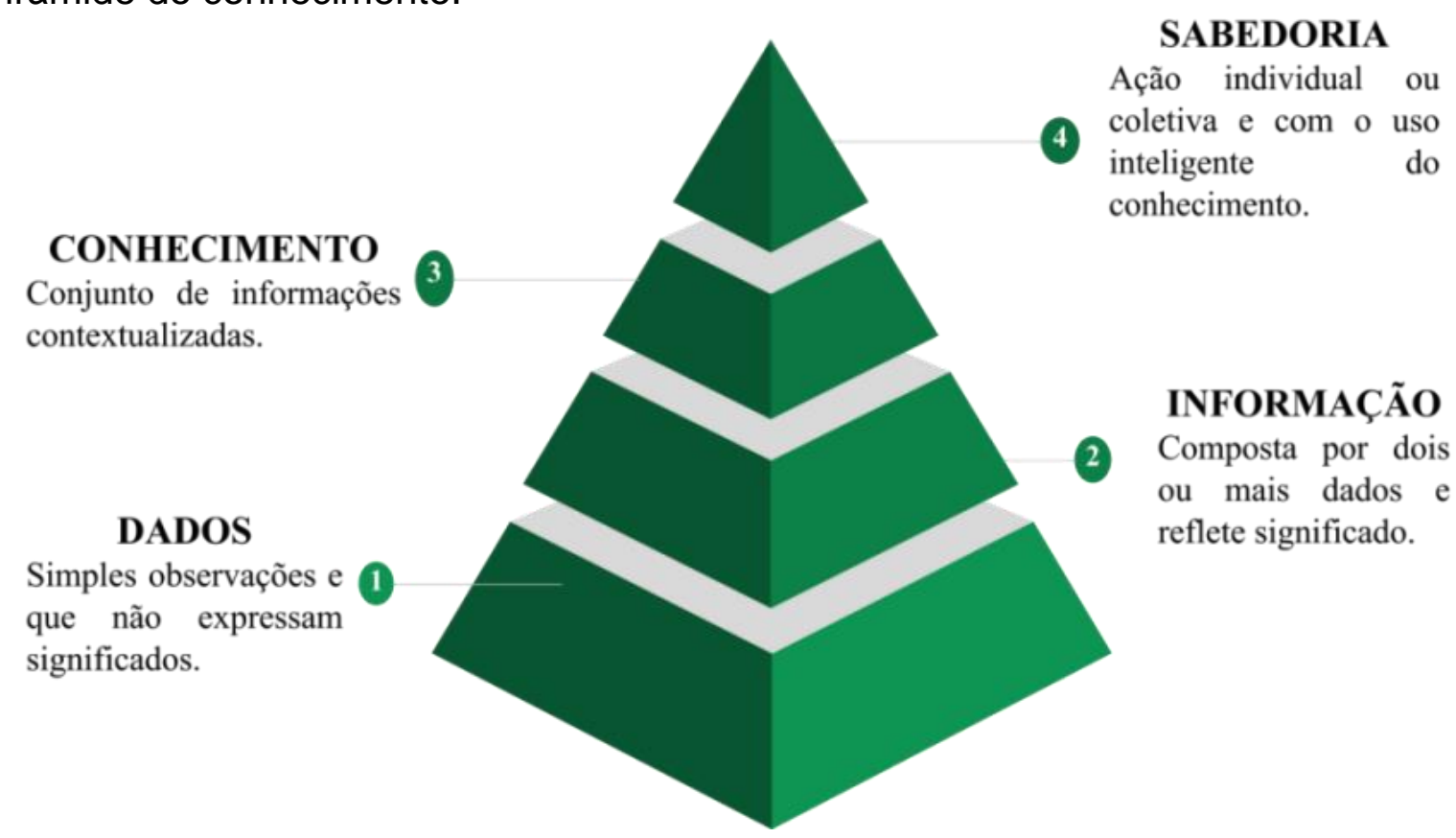

Fonte: Ackoff ,1989. 
Portanto, admite-se que conhecimento é ter informação, ou seja, aquilo que pode ser usado ou acessado por alguém. Por sua vez, para alcançar a sabedoria é necessário que, além de se ter acesso ao conhecimento, é preciso saber utilizá-los em todas as situações.

Gestão do conhecimento, gestão da informação e inteligência competitiva

Dalkir (2011) diz que gestão do conhecimento é a administração sistematizada de pessoas, tecnologias, processos e estrutura organizacional com o propósito de atribuir valor à organização por meio da inovação, criação, compartilhamento e a prática do conhecimento.

A gestão do conhecimento é a composição basilar da estratégia organizacional e o conhecimento, ou inteligência, é o produto da integração entre os indivíduos de uma instituição. Nonaka (2000) afirma que as organizações exitosas são aquelas que, intencionalmente, geram conhecimento, transmitindo-o a todos e implementando-o imediatamente a novas tecnologias, produtos ou serviços.

As organizações públicas são "grandes produtores e consumidores de conhecimento" (Pardo et al, 2013, p. 1164), por isso, necessitam concentrar seus esforços no uso eficiente dos recursos públicos e na prestação de serviços de qualidade aos seus cidadãos. Dessa maneira a gestão do conhecimento na gestão pública é diretamente relacionada ao conhecimento público e se bem articulados podem ser usados no desenvolvimento de uma administração de qualidade (Bem; Prado; Delfino, 2013).

Para que esta prática se inicie reconhece-se que a informação é a matéria-prima da gestão do conhecimento (Rodrigues; Blattmann, 2014). Para bem administrar sua qualidade e conteúdo os mesmos autores afirmam que é necessário identificar quais suas fontes:

Pode-se definir fontes de informação como tudo o que gera ou veicula informação. Pode ser descrita como qualquer meio que responda a uma necessidade e informação por parte de quem necessita, incluindo produtos e serviços de informação, pessoas ou rede de pessoas, programas de computador, meios digitais, sites e portais (Rodrigues; Blattmann, 2014, p. 10).

Inteligência competitiva se diferencia dos demais conceitos porque tem como objetivo ampliar as possibilidades de competitividade, direcionando o modelo de negócios, planejamento estratégico e demais norteadores de uma organização. Cubillo (1997) define inteligência competitiva como o

conjunto de capacidades próprias mobilizadas por uma entidade lucrativa, destinadas a assegurar o acesso, capturar, interpretar e preparar conhecimento e informação com alto valor agregado para apoiar a tomada de decisão requerida pelo desenho e execução de sua estratégia competitiva. (p. 261)

É possível inferir, portanto, que inteligência competitiva é a forma que as instituições, públicas ou privadas, podem se antecipar às exigências impostas pelo mercado e implica em saber utilizar as informações disponíveis - cliente, concorrentes e fornecedores - de maneira estratégica. 
É possível enumerar algumas vantagens ao se utilizar a inteligência competitiva, conforme estudos de Gomes e Braga (2017): é possível criar uma base de informações para amparar o processo decisório; prever comportamentos ou estabelecer padrões a respeito do mercado consumidor e ações dos concorrentes; pode-se identificar necessidades e perspectivas para agir antecipadamente oferecendo inovações em seus produtos ou serviços.

Os três conceitos apresentados são muito semelhantes e diretamente relacionados, em virtude disto a ação de um reflete no outro, existindo uma hierarquização entre eles além das tecnologias de informação que os permeiam.

Quadro 1 -

Relação de hierarquização entre os conceitos derivados do conhecimento.

\begin{tabular}{|l|l|l|}
\hline \multicolumn{1}{|c|}{ Gestão do conhecimento } & \multicolumn{1}{|c|}{ Gestão da informação } & \multicolumn{1}{|c|}{ Inteligência competitiva } \\
\hline Alvo: capital intelectual. & Alvo: modelo de negócio. & Alvo: estratégias. \\
\hline $\begin{array}{l}\text { Exemplo: desenvolvimento } \\
\text { da cultura organizacional } \\
\text { voltado para o conhecimento. }\end{array}$ & $\begin{array}{l}\text { Exemplo: divulgação e } \\
\text { conciliação da informação ao } \\
\text { público interessado. }\end{array}$ & $\begin{array}{l}\text { Exemplo: utilização de } \\
\text { sistemas de informações } \\
\text { direcionado para gestão de } \\
\text { decisões estratégicas. }\end{array}$ \\
\hline $\begin{array}{l}\text { Age principalmente com } \\
\text { fluxos informais da } \\
\text { informação. }\end{array}$ & $\begin{array}{l}\text { Atua fundamentalmente com o } \\
\text { fluxo formal de informações. }\end{array}$ & $\begin{array}{l}\text { Trabalha necessariamente } \\
\text { com os fluxos informais e } \\
\text { formais da informação. }\end{array}$ \\
\hline
\end{tabular}

Fonte: Valentim, 2002.

A conexão entre as três definições existe, pois as informações e os conhecimentos são insumos para a estruturação de cada um dos modelos. O que se altera de um para 0 outro é a complexidade e as ações envolvidas.

$\mathrm{Na}$ gestão do conhecimento a complexidade acontece pelo conhecimento tácito muito encontrado nas organizações, ou seja, um ou mais indivíduos compartilham suas experiências, percepções, valores e sentimentos. Já quando se trabalha com a gestão da informação lida-se com o conhecimento explícito, formal, presentes em registros históricos oficiais das organizações.

Por sua vez, a complexidade da inteligência competitiva está caracterizada no estabelecimento de ligações e relacionamentos que devam gerar inteligência nas instituições, para que a partir delas sejam criadas estratégias e dessa forma assegurar a melhor tomada de decisão.

São com estes conceitos que gestores poderão aplicar o conhecimento, que é considerado um recurso chave para manter a competitividade e a sustentabilidade organizacional (Nonaka; Takeuchi, 1997).

Data mining no ambiente acadêmico

Fazer a gestão de dados é um dos desafios nas instituições de ensino superior, visto que o seu volume vem crescendo exponencialmente (Romero; Ventura, 2013). Por isso, nos últimos anos, a mineração de dados vem tomando espaço, principalmente na coleta, análise e interpretação dos dados (Baker; Isotani; Carvalho, 2011). 
A mineração de dados - data mining, DM - tem se mostrado promissora por conseguir acolher um grande volume de informações que, se bem analisadas, podem se tornar um diferencial competitivo na IES. A DM é relacionada com a descoberta do conhecimento útil, oportuno e compreensível (Torgo, 2017). A mineração de dados já é realidade e tem apresentado resultados satisfatórios em algumas áreas, como é o caso da medicina, das instituições financeiras e no processo de tomada de decisão (Witten; Frank; Hall, 2011).

A DM dedica-se, sobretudo, em extrair informações que sejam relevantes num universo variado de dados. Essa triagem é feita de maneira automatizada, ou pelo menos aprimorada, por meio de softwares. Por eles são descobertos episódios-padrão que representem relevância, para que dessa maneira possam ser descobertos ou gerados novos conhecimentos (Witten; Frank; Hall, 2011).

O processo de DM começa com os dados, que pode ser uma simples coletânia de observações numéricas até uma matriz complexa com milhares de variáveis (Kotu; Deshpande, 2015). Esse tipo de tratamento tem sido usado nas mais diversas áreas para identificar padrões de comportamento e identificar insights que gerem melhorias em produtos e serviços. No âmbito educacional a mineração de dados ainda é um tipo de tecnologia emergente, tanto no ambiente virtual de aprendizado, quanto na gestão estratégica de dados acadêmicos (Daniel, 2016).

Neste trabalho a apresentação do DM torna-se essencial para entender como dados iguais podem ser trabalhados de maneiras distintas, de acordo com a necessidade e 0 modelo de negócio do IFS. A mineração de dados educacionais atrelada ao Power BI@ proporciona uma gama de novas possibilidades de análise, monitoramento e controle dos principais eixos estratégicos da gestão acadêmica.

Business intelligence - $\mathrm{BI}$

A partir dos anos 1980 os dados começaram a ter a devida atenção, momento este em que apareceram a administração de dados, modelagem de dados e banco de dados relacional (Barbieri, 2011). Em 1990, com a disseminação da internet relacionada a transformação do uso de dados, aproveitamento da informação e evolução das tecnologias, os dados começaram a ter destaque e crescimento exponencial na utilização das plataformas digitais para compras, vendas, relacionamento com clientes e fornecedores.

No Quadro 2 é possível esquematizar as informações apresentadas sobre os principais autores que tratam deste assunto e os seus respectivos conceitos sobre BI. 
Quadro 2 -

Síntese de autores e conceitos sobre Bl.

\begin{tabular}{|c|l|}
\hline Autor & \multicolumn{1}{c|}{ Conceito de BI } \\
\hline Luhn (1958) & Sistema automático para disseminar informação. \\
\hline Barbieri (2011) & $\begin{array}{l}\text { Associado à expressão: guarda-chuva conceitual, que fala do agrupamento } \\
\text { de dados, informaçose e conhecimento. }\end{array}$ \\
\hline Barbieri (2011) & $\begin{array}{l}\text { Trata do uso de "variadas fontes de informação que vão definir estratégias } \\
\text { de competitividade nos negócios da empresa, através do uso de banco de } \\
\text { dados que buscam fatos relacionados e subliminares. }\end{array}$ \\
\hline Melo (2014) & $\begin{array}{l}\text { Sistema completo e sinérgico, que enlaça desde a captação, verificação e } \\
\text { validação de dados de uma ponta a outra de qualquer relação comercial. }\end{array}$ \\
\hline
\end{tabular}

Fonte: autores, 2020.

O BI é também reconhecido como inteligência nos negócios ou inteligência empresarial e tratado como mecanismo para tomada de decisão assertiva utilizando dados e informações disponíveis nos mais diferentes sistemas de informação de uma organização (Silva et al, 2016). A escolha da ferramenta de BI numa organização pública depende não apenas de investimento financeiro que será requisitado, nem do tipo de banco de dados que já utilizado, mas do capital técnico e operacional daqueles servidores que irão trabalhar com os dados.

Dentro de uma instituição pública, o envolvimento entre os servidores que entendem das regras de negócio com aqueles que irão trabalhar com análise dos dados e daqueles que irão usufruir da informação gerada é condição necessária para o sucesso de qualquer objetivo estratégico.

\section{Metodologia}

Para este trabalho foram utilizadas informações do Sistema Integrado de Gestão de Atividades Acadêmicas - Sigaa. Para acessar ao Sigaa foi necessário requerer a autorização institucional. Liberado 0 acesso, foram realizados diversos testes e simulações para verificar os tipos e forma que as informações são apresentadas aos gestores. A partir destes experimentos foi possível compreender como as informações prestadas pelo Sigaa são encontradas e quais ações de transformações deveriam ser realizadas para melhor aproveitamento e uso na composição do painel de gestão.

Inicialmente foi gerado o documento Alunos concluintes nos cursos de graduação, por status e gênero 2018. Esse relatório possui as seguintes características: arquivo em PDF, 5 páginas, 12 quadros - um para cada curso - e todos compostos por seis colunas, sendo elas: número de matrícula, nome do aluno, sexo, status, semestre de saída e data de nascimento. 
Figura 3 -

Relatório bruto Sigaa: concluintes 2018.
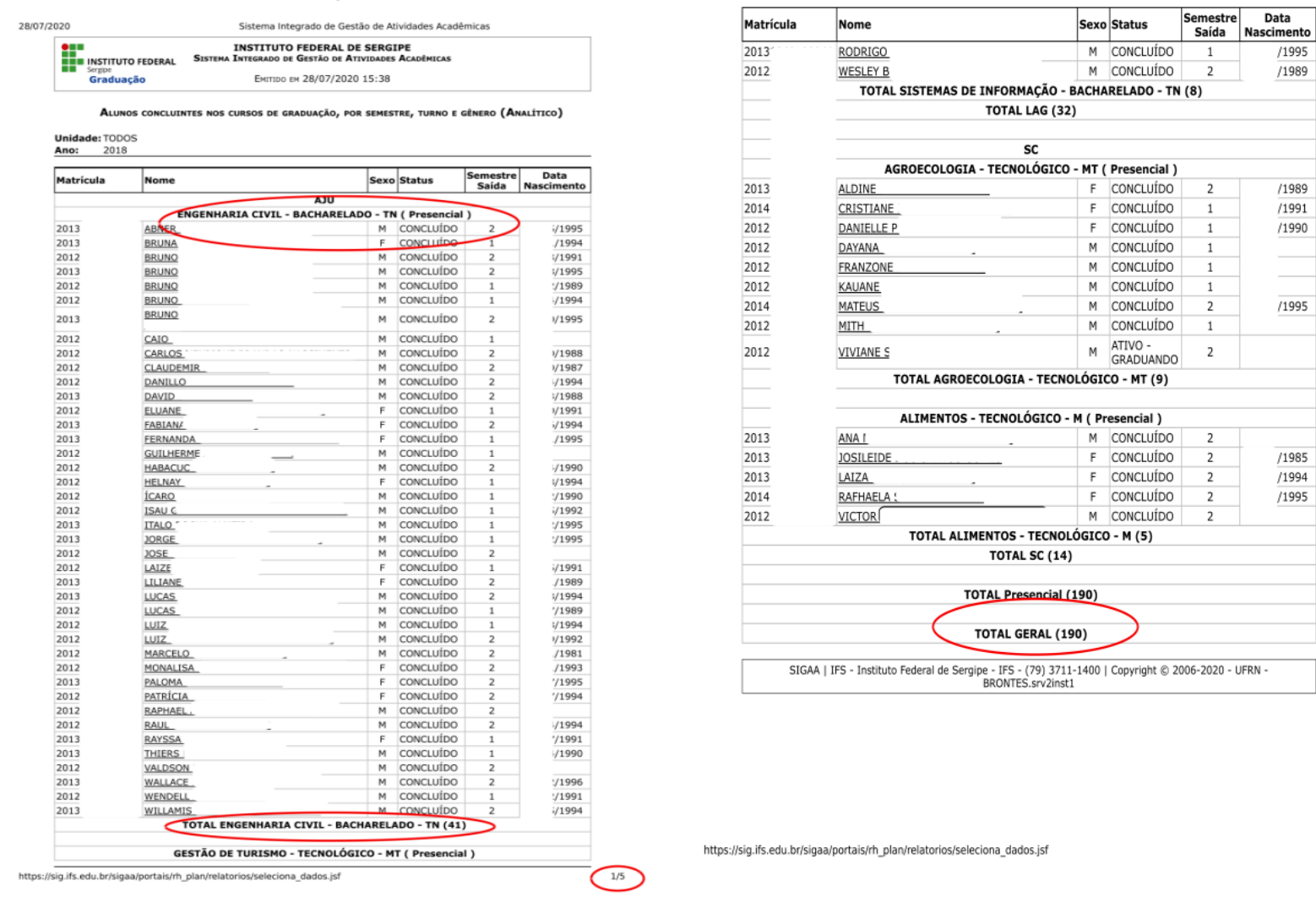

Fonte: Sigaa/IFS, 2020.

Em termos gerenciais, e para quaisquer tipos de apresentação para auxiliar o processo decisório, em nada importa as duas primeiras colunas. O status se torna redundante, pois, o relatório é de concluintes, portanto, os alunos necessariamente precisam ter cumprido $80 \%$ ou mais da carga horária mínima do currículo, informação essa que se repete nas mais de 200 linhas do documento. Há uma linha-resumo no fim de cada quadro quantitativo de concluintes daquele curso. Da forma apresentada não é percebida a utilidade da última coluna onde há a data de nascimento do aluno, pois não é possível inferir, por exemplo, a idade média do concluinte.

$\mathrm{Na}$ parte final deste mesmo relatório é possível obter a informação de quantos alunos são caracterizados como concluintes naquele ano de 2018, sendo 190. Não há quadro resumo das informações - concluintes por curso e por semestre, por exemplo - e também não há origem do aluno, se rede privada ou pública. Porém, estas informações podem ser obtidas por meio de outros documentos separados, sem possibilidade de mesclagem entre eles. Caso houvesse a chance de cruzamento entre os relatórios haveria maior relevância no conteúdo para que o gestor tivesse mais segurança ao tomar qualquer decisão.

Numa segunda análise houve também a exploração do relatório que mostra o espectro de renda. Na figura 4 é possível observar que o documento é composto por duas colunas: número de salários e número de alunos. Ao contrário do anterior é bem sucinto e de rápida leitura, porém, a qualidade e credibilidade da informação são comprometidos 
quando se analisa o número de salários. Sabe-se que é pouco provável que alguém receba acima de 200 salários mínimos e esse tipo de ocorrência é percebida em vários trechos do documento, caracterizando uma falha no cadastramento das faixas salariais.

Figura 4 -

Relatório bruto Sigaa: espectro de renda.

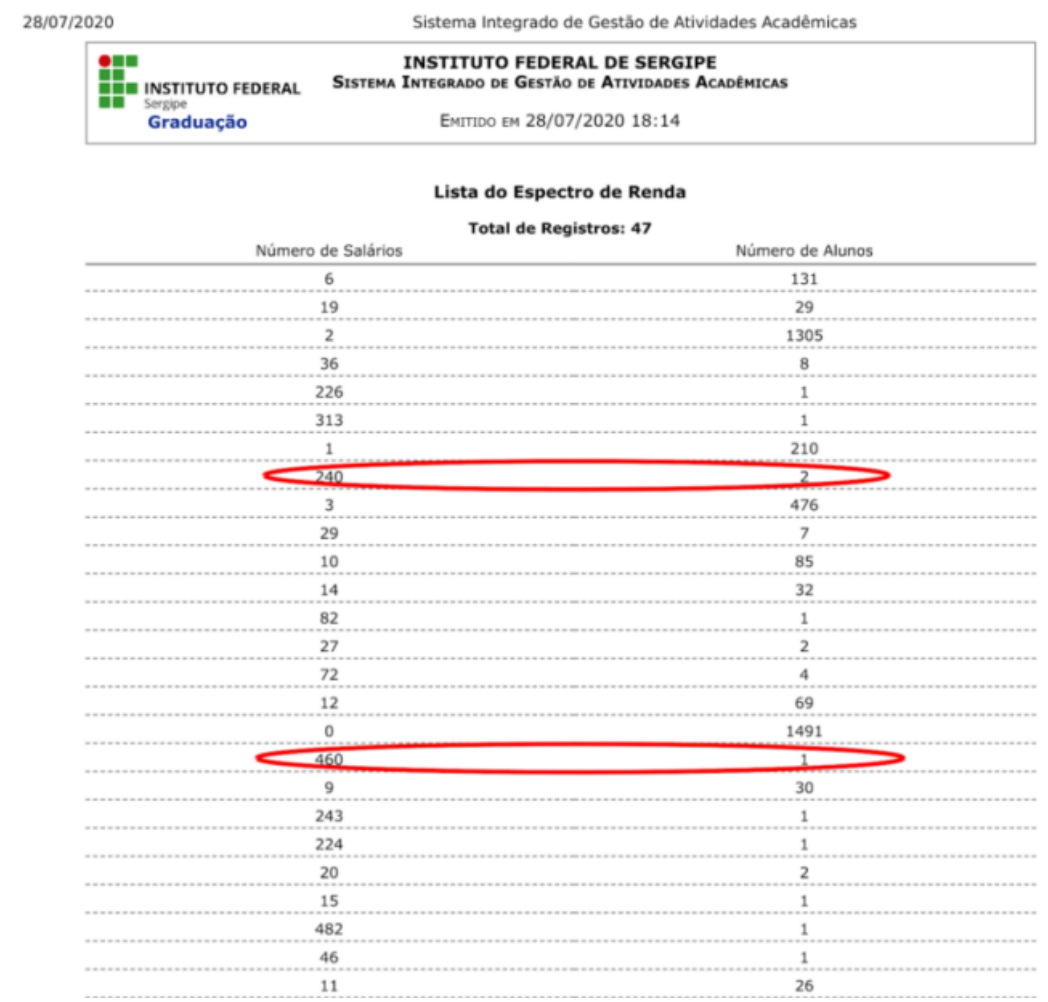

Fonte: Sigaa/IFS, 2020.

Compreendido o modo de exibição e disposição das informações foi possível limitar quais informações seriam usadas para geração do painel de gestão aproveitando a base de dados existente e da maneira mais eficiente possível. Com base no método foram coletadas e analisadas informações da literatura com temática semelhante em livros, dissertações, teses e artigos considerando as seguintes variáveis: business intelligence, transparência, gestão do conhecimento, ensino superior público e Power $\mathrm{BI}$.

\section{Análise dos dados: informações e indicadores eleitos}

Nesta seção serão apresentadas as principais informações que irão compor o painel de gestão acadêmica para o IFS. Esta delimitação se faz necessária não para eleger qual o dado mais importante, pois todos o são, mas apenas para se ater ao objeto da pesquisa, que é a gestão acadêmica. Por isso, nas próximas subseções serão elencadas as principais variáveis que serão captadas do Sigaa e, a partir disso, fazer uso dos dados para cálculo e demonstração dos indicadores exigidos pelo Tribunal de Contas da União TCU - e Ministério da Educação. 
Seleção das informações fornecidas pelo Sigaa

Os tipos de relatórios originados pelo Sigaa não fornecem informações resumidas ou possibilidades de relatórios personalizados, como a mesclagem entre eles ou cálculos de média aritmética simples, por exemplo.

Com os relatórios do Sigaa foram coletadas informações relevantes para a construção dos dashboards que constituirão o painel de gestão acadêmica proposto ao IFS. A escolha das variáveis e áreas que são tratadas no painel de gestão foram eleitas em conjunto com a equipe da Pró-reitoria de Ensino por meio de uma pesquisa não estruturada. As informações disponibilizadas no sistema são limitadas, por isso neste trabalho os dados estão concentrados nos anos de 2018 e 2019. Apesar deste afunilamento temporal ainda será possível se apropriar de uma gama de novos conhecimentos que serão exibidos pelo Power $B \mid{ }^{\circledR}$.

A partir da coleta e do tratamento de dados extraídos de vários relatórios será possível derivar as seguintes informações:

1) Cursos: serão expostas características e propriedades dos cursos de graduação que se formataram ao longo do tempo ${ }^{3}$ em nível institucional;

2) Situação de matrícula: delinear qual a situação e quantitativo de alunos que se mantém regulares, que trancaram, evadiram ou concluíram o curso;

3) Classificação racial e renda: será possível conhecer o perfil daqueles que participaram dos últimos processos seletivos e comparar com as particularidades do aluno regular;

4) Sexo e faixa etária: a partir deste conhecimento será possível ajustar ou regulamentar ações sociais específicas para atendimento assertivo do aluno;

5) Docentes: acompanhamento dos quantitativos sobre titulação, afastamentos, tipo de vínculo e carga horária são essenciais para realizar alocações ou instituir ações estratégicas que tenham o professor como protagonista;

6) Concluintes: monitorar o número de concluintes por curso, semestre e ano não é apenas uma exigência do MEC e TCU, mas principalmente um diferencial para aferir a eficiência de ensino e conseguir estipular programas de acompanhamento aos egressos;

7) Evasão: ter conhecimento do número de alunos que desistem da sua vida escolar pode levar a razões que impulsionaram esta ação e de posse deste panorama é viável articular algum plano de trabalho que evite ou reverta o cenário indesejado.

O desafio na geração do painel de gestão é o agrupamento das informações presentes em relatórios diferentes disponibilizados pelo Sigaa. Por isso faz-se necessário um tratamento minucioso dos dados para que sejam conjugadas informações estratégicas necessárias e gerada a possibilidade de exploração de novos aprendizados.

As principais variáveis brutas para formatação do painel de gestão capturadas do Sigaa são: sexo, data de nascimento, curso, turno, tipo de ingresso, espectro de renda, tipo de deficiência e situação da matrícula. A partir destas premissas, no Power $\mathrm{BI}$ ( ) foi possível realizar simples cálculos totais, média aritmética, idade e faixa etária, faixa de renda e demais cruzamentos que se fizeram oportunos.

3 Os dados disponíveis no Sigaa sobre informações dos processos seletivos são referentes aos editais 01/2019/DAA/Proen e 06/2019/DAA/Proen.

Regae: Rev. Gest. Aval. Educ. Santa Maria

v. 10

n. 19

e64035, p. 1-22

2021 
As demais informações disponibilizadas nos relatórios, como nome, matrícula, endereço, telefone e e-mail foram desconsideradas por não ter relevância gerencial nesta análise. É importante ressaltar que as variáveis sexo, cor, tipo de deficiência e renda são opções que permitem a auto-declaração do estudante, havendo somente a limitação de campos imposto pelo sistema.

Indicadores fixados pelo acórdão n. 2.267/2005/TCU

Ainda em 2002 o TCU percebeu que algumas universidades não possuíam dados considerados básicos para a elaboração de indicadores. Algumas delas também apresentavam resistência em disponibilizar seus dados ou promover a medição dos seus resultados, seja de forma qualitativa ou quantitativa (TCU, 2002).

A qualidade e a disponibilidade destas informações são essenciais para acompanhamento da evolução e para o planejamento e desenvolvimento de políticas públicas voltadas para educação. Por conta desta ausência na prestação de dados e na despadronização deu-se origem aos acórdãos 2.267/2005, 104/2011 e 2.508/2011 do TCU/Plenário. As exigências contidas nestes documentos passaram a ser obrigatórias para os institutos federais e estes, por sua vez, deveriam a partir de então prestar contas anualmente.

O monitoramento das ações da educação pelo TCU é fundamental para garantir que as atividades das IES da rede federal sejam desenvolvidas em direção ao cumprimento dos compromissos firmados pelo MEC e pela Secretaria de Educação Profissional e Tecnológica.

Os indicadores apontados no acórdão n. 2.267/2005, ainda vigente, permitem aferir e acompanhar a eficiência de além de atender as metas estabelecidas no PNE. A seguir, segue fragmento do acórdão que balizou as escolhas apropriadas ao objeto de pesquisa. Foram selecionados, com base nos critérios de relevância acadêmica e gerencial, os onze abaixo listados para integrarem a prestação de contas das instituições de ensino:

1) relação candidato/vaga;

2) relação ingressos/aluno;

3) relação concluintes/aluno;

4) índice de eficiência acadêmica de concluintes;

5) índice de retenção do fluxo escolar;

6) relação de alunos/docente em tempo integral;

7) índice de titulação do corpo docente;

8) gastos correntes por aluno;

9) percentual de gastos com pessoal;

10) percentual de gastos com outros custeios;

11) percentual de gastos com investimentos.

Os indicadores considerados para confecção do painel de gestão acadêmica serão: relação candidato/vaga $(\mathrm{RCV})$; relação ingresso/matriculado (RIM); relação concluinte/matriculado (RCM); índice de eficiência acadêmica (EAC); índice de retenção do fluxo escolar (RFE); e relação de alunos/docentes (RAD). Para geração destes indicadores, especificamente nesta pesquisa, serão utilizadas informações específicas coletadas em relatórios do Sigaa. 
Definidos os indicadores pelo TCU e tendo acesso indireto ao banco de dados do IFS foi possível manter essa informação atualizada e disponível a qualquer tempo para consulta dos gestores. Afinal, a apresentação destes resultados impactam não apenas na transparência da gestão, mas deriva mais uma forma de diagnóstico e conhecimento sobre o próprio modelo de negócio do Instituto.

Indicadores determinados pelo MEC

Até agora sabe-se que o painel de gestão será composto das informações explicitadas anteriormente, contudo ainda se faz necessário incluir informações recentemente deliberadas pelo MEC no que diz respeito aos indicadores de qualidade do ensino superior regulamentados pela portaria n. 429/2020/MEC. Neste documento estão instituídos as seguintes medições: a) conceito Enade; b) indicador de diferença entre os desempenhos observado e esperado - IDD; c) conceito preliminar de curso - CPC; d) índice geral de cursos - IGC.

Os referidos indicadores serão calculados a partir de insumos oriundos das seguintes fontes: Enade, Enem, Censo e pela avaliação dos programas de pós-graduação stricto sensu da Capes. Por meio do quadro 3 é possível compreender quais resultados serão obtidos a partir do cálculo de cada indicador.

Quadro 3 -

Indicadores de qualidade do ensino superior regulamentados pela portaria $\mathrm{n}$. 429/2020/MEC.

\begin{tabular}{|c|l|}
\hline Indicador & \multicolumn{1}{|c|}{ Medições esperadas } \\
\hline \multirow{5}{*}{$\begin{array}{c}\text { Conceito } \\
\text { Enade }\end{array}$} & $\begin{array}{l}\text { Avalia os cursos de graduação a partir dos resultados obtidos pelos estudantes } \\
\text { no Enade. É divulgado anualmente para os cursos em que pelo menos dois } \\
\text { estudantes concluintes participaram do exame. O cálculo do Conceito Enade } \\
\text { leva em consideração o número de estudantes participantes no exame com } \\
\text { resultados válidos; o desempenho dos estudantes participantes na parte de } \\
\text { Formação Geral do exame; e o desempenho dos estudantes participantes na } \\
\text { parte de componente específico do exame }\end{array}$ \\
\hline IDD & $\begin{array}{l}\text { Mede o valor agregado pelo curso ao desenvolvimento dos estudantes } \\
\text { concluintes. Para isso, considera os desempenhos no Enade e no Enem. O } \\
\text { cálculo trabalha com o número de estudantes concluintes participantes no } \\
\text { Enade com resultados válidos; o desempenho geral dos estudantes } \\
\text { participantes no Enade; o desempenho dos estudantes no Enem nas áreas de } \\
\text { ciências da natureza, ciências humanas, linguagens e matemática; e o número } \\
\text { de participantes no Enade com a nota do Enem recuperada. }\end{array}$ \\
\hline $\begin{array}{l}\text { Combina, em uma única medida, diferentes aspectos relativos aos cursos de } \\
\text { graduação: desempenho dos estudantes, valor agregado pelo processo } \\
\text { formativo oferecido pelo curso, corpo docente e percepção dos estudantes } \\
\text { sobre as condições de ensino ofertado pela instituição. Leva em consideração } \\
\text { a nota dos concluintes no Enade; a nota do IDD; a proporção de professores } \\
\text { mestres; a proporção de professores doutores; a proporção de professores em } \\
\text { regime de trabalho parcial ou integral; a média das respostas do questionário } \\
\text { do estudante referentes à organização didático-pedagógica; a média das } \\
\text { respostas do questionário do estudante referentes à infraestrutura e às } \\
\text { instalações físicas; e a média das respostas do questionário do estudante } \\
\text { referentes às oportunidades de ampliação da formação acadêmica e } \\
\text { profissional. }\end{array}$ \\
\hline
\end{tabular}


\begin{tabular}{|c|l|}
\hline \multirow{6}{*}{ IGC } & $\begin{array}{l}\text { Resulta da avaliação das IES. É uma média ponderada, a partir da distribuição } \\
\text { dos estudantes nos níveis de ensino, que envolve as notas contínuas do CPC } \\
\text { e dos conceitos atribuídos pela Capes. O cálculo do IGC leva em consideração } \\
\text { as notas contínuas de CPC referentes aos cursos de graduação avaliados por } \\
\text { triênio, considerando o CPC mais recentemente publicado para cada curso; o } \\
\text { número de matrículas nos cursos de graduação; os conceitos dos cursos de } \\
\text { mestrado e doutorado atribuídos pela Capes na última avaliação divulgada } \\
\text { oficialmente; e o número de matrículas nos cursos de mestrado e doutorado, } \\
\text { conforme base de dados oficial encaminhada pela Capes ao Inep. }\end{array}$ \\
\hline
\end{tabular}

Fonte: Inep, 2020.

Além de serem utilizados para embasar políticas públicas e orientar as IES na busca por melhorias, os indicadores devem ser observados pela sociedade em geral, pois valem como referência quanto às condições de ensino de cursos e instituições (Inep, 2020).

\section{Resultado: painel de gestão acadêmica}

Serão apresentados os dashboards a partir das informações eleitas e apresentadas na seção anterior. Segundo Lago e Alves (2018) um dos diferenciais do Power BI® é a capacidade de tratamento dos dados e aqui será apresentado as principais etapas para construção deste produto técnico.

Para a elaboação deste painel seguiu-se a seguinte sequência:

1) Trabalho no Power Query Editor: no qual foi realizada a importação, conexão e tratamentos dos dados. Nesta fase foi feita integração dos relatórios em PDF exportados do Sigaa. Foi nesse momento que ocorreu a padronização e filtros dos dados para que houvesse a conjugação e convergência das informações.

2) Modelagem dos dados: nesta etapa foram cruzados vários relatórios para que se obtivessem os relacionamentos entre eles e a partir de então pudessem ser geradas novas medidas para gerar algum conteúdo. A interface visual desta ferramenta é simples e similar aos cálculos encontrados nas planilhas eletrônicas, como no Excel, por exemplo.

3) Visualização dos dados: última etapa de construção do painel de gestão. O Power $\mathrm{BI}{ }^{\circledR}$ oferece uma grande cartela de opções de visualizações: gráficos, matrizes, cartões, mapas etc. Além disso, permite a criação de um novo visual, se assim for a necessidade do usuário. Para esta pesquisa, todas as visualizações utilizadas são aquelas já disponibilizadas pelo sistema.

Para a elaboração dos dashboards poderia ter sido utilizada uma conexão direta com o banco de dados da Instituição, contudo, o acesso permitido foi apenas pelo Sigaa. Portanto, a partir de relatórios padrão oferecidos pelo sistema utilizado atualmente foi possível a geração de arquivos em PDF para que pudesse haver um tratamento adequado do que se pretendia.

Extraídos os relatórios e armazenado localmente foi elaborado, com base na seleção de dados expostos nas subseções anteriores, o painel de gestão com informações temáticas sobre processo seletivo, perfil do discente, concluintes, evasão, docentes, indicadores firmados pelo acórdão n. 2.267/2005/TCU e pela portaria n. 
429/2020/MEC. As informações selecionadas não abarcam todo o ambiente acadêmico, contudo, não prejudica o desenvolvimento desta investigação, visto que o objetivo é propor um modelo que possa ser utilizado pelo IFS.

Para uma melhor compreensão apresenta-se no quadro 4 o resumo sobre a abordagem de cada visualização que compõe o painel de gestão acadêmica.

\section{Quadro 4 -}

Descrição do painel de gestão acadêmica.

\begin{tabular}{|c|c|}
\hline Referencial & Dashboards \\
\hline \multirow{5}{*}{$\begin{array}{l}\text { Seleção das informações fornecidas } \\
\text { pelo Sigaa }\end{array}$} & Dashboard 1 - Processo seletivo 2019 \\
\hline & Dashboard 2 - Perfil do discente regular institucional \\
\hline & Dashboard 3 - Concluintes | comparativo 2018/ 2019 \\
\hline & Dashboard 4 - Evasão 2018/2019 \\
\hline & Dashboard 5 - Docentes \\
\hline $\begin{array}{l}\text { Indicadores fixados pelo acórdão } \mathrm{n} \text {. } \\
2.267 / 2005 / \mathrm{TCU}\end{array}$ & $\begin{array}{l}\text { Dashboard } 6 \text { - Indicadores fixados pelo acórdão n. } \\
2.267 / 2005 / T C U\end{array}$ \\
\hline $\begin{array}{l}\text { Indicadores } \quad \text { estabelecidos } \\
\text { portaria n. } 429 / 2020 / M E C\end{array}$ & $\begin{array}{l}\text { Dashboard } 7-\text { Indicadores regulamentados pela } \\
\text { portaria n. } 429 / 2020 / M E C\end{array}$ \\
\hline
\end{tabular}

Fonte: autores, 2020.

Figura 5 -

Dashboard 1: processo seletivo 2019.

\section{PERFIL DO DISCENTE REGULAR_INSTITUCIONAL | 2019.2}

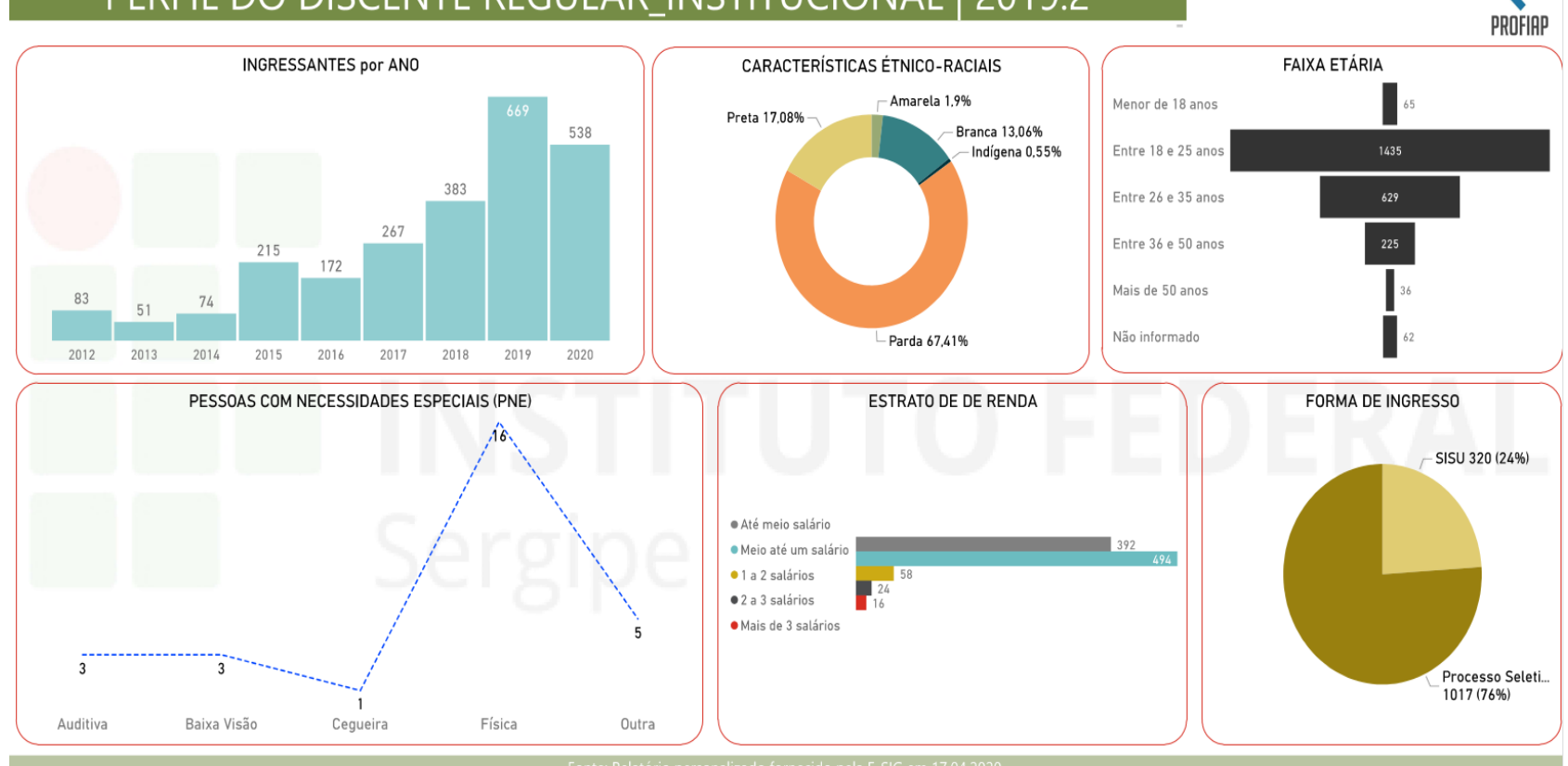

Fonte: elaborado pelos autores no Power BI Desktop, 2020. 
Figura 6 -

Dashboard 2: perfil do discente regular institucional.

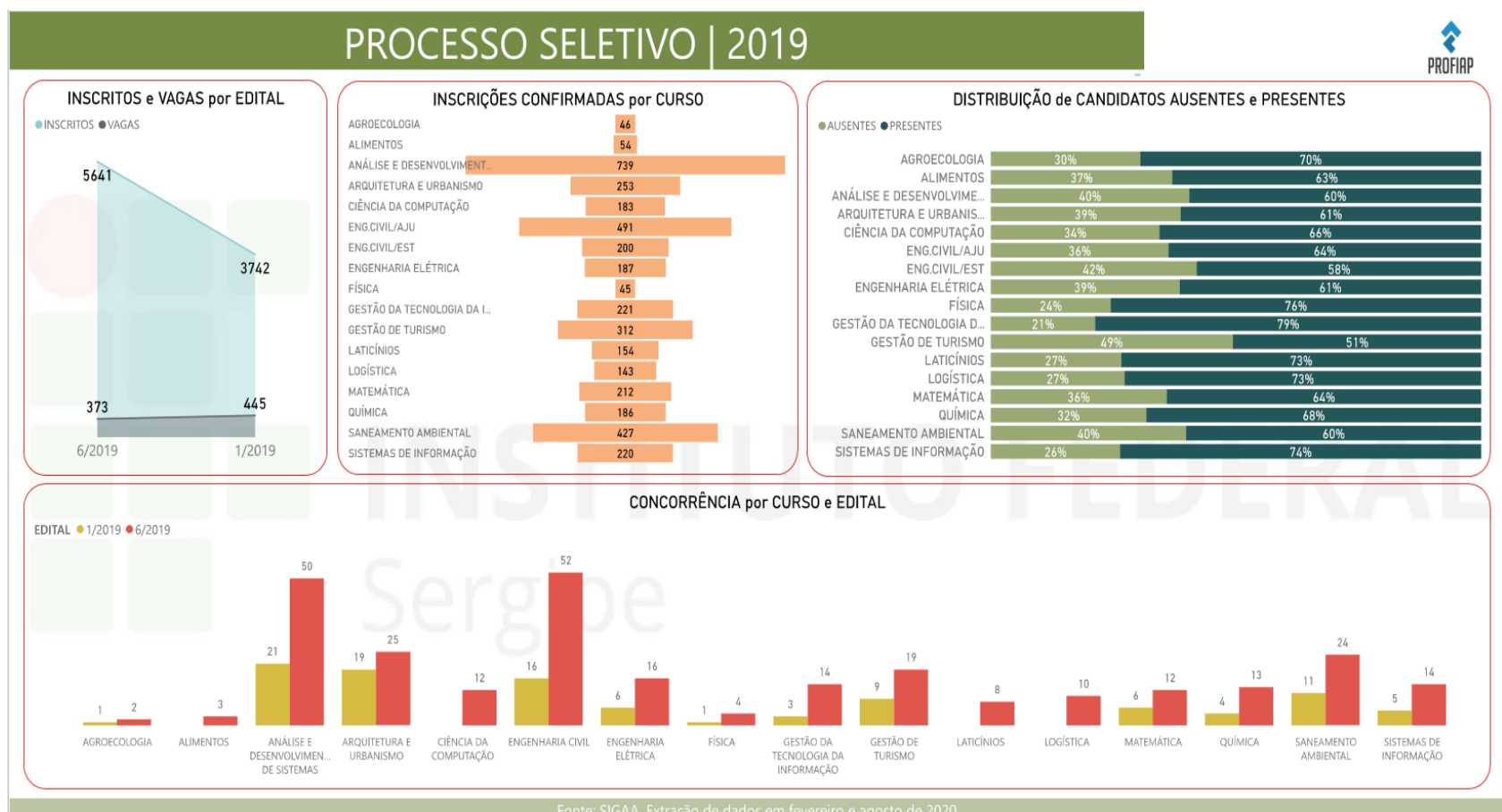

Fonte: elaborado pelos autores no Power BI Desktop, 2020.

Figura 7 -

Dashboard 3: concluintes | comparativo 2018/2019.

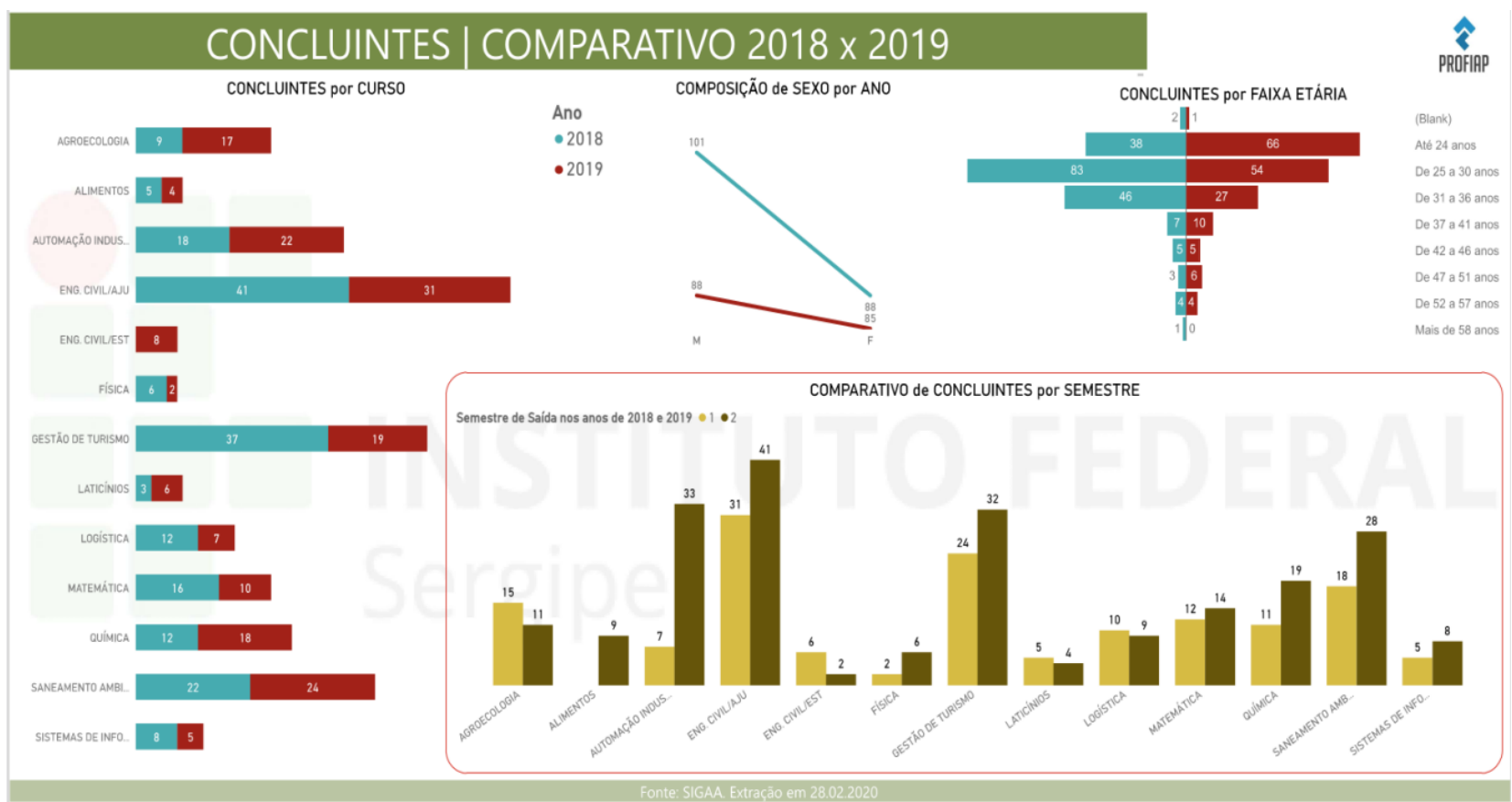

Fonte: elaborado pelos autores no Power BI Desktop, 2020. 
Figura 8 -

Dashboard 4: evasão 2018/2019.

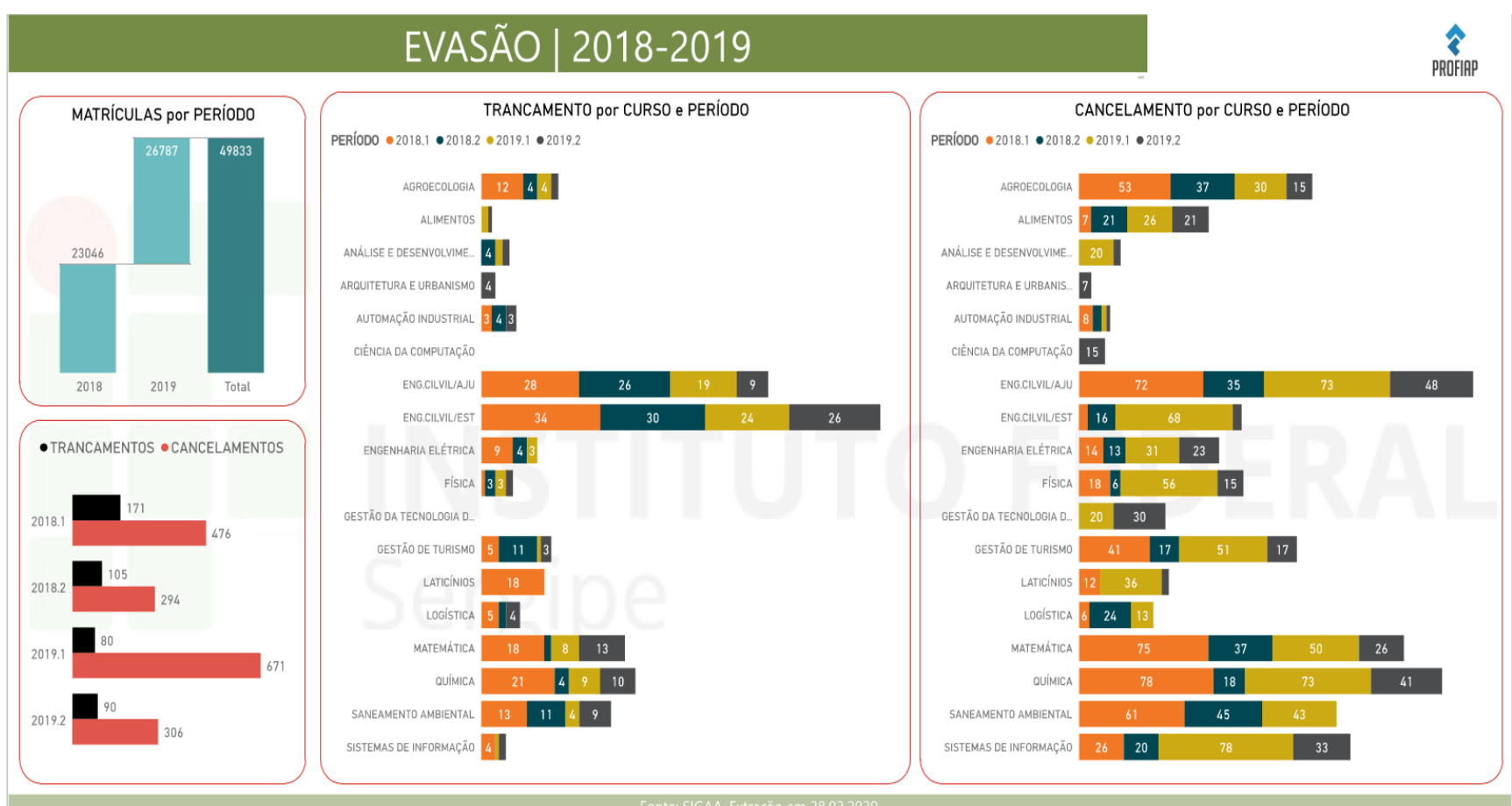

Fonte: elaborado pelos autores no Power BI Desktop, 2020.

Figura 9 -

Dashboard 5: docentes.

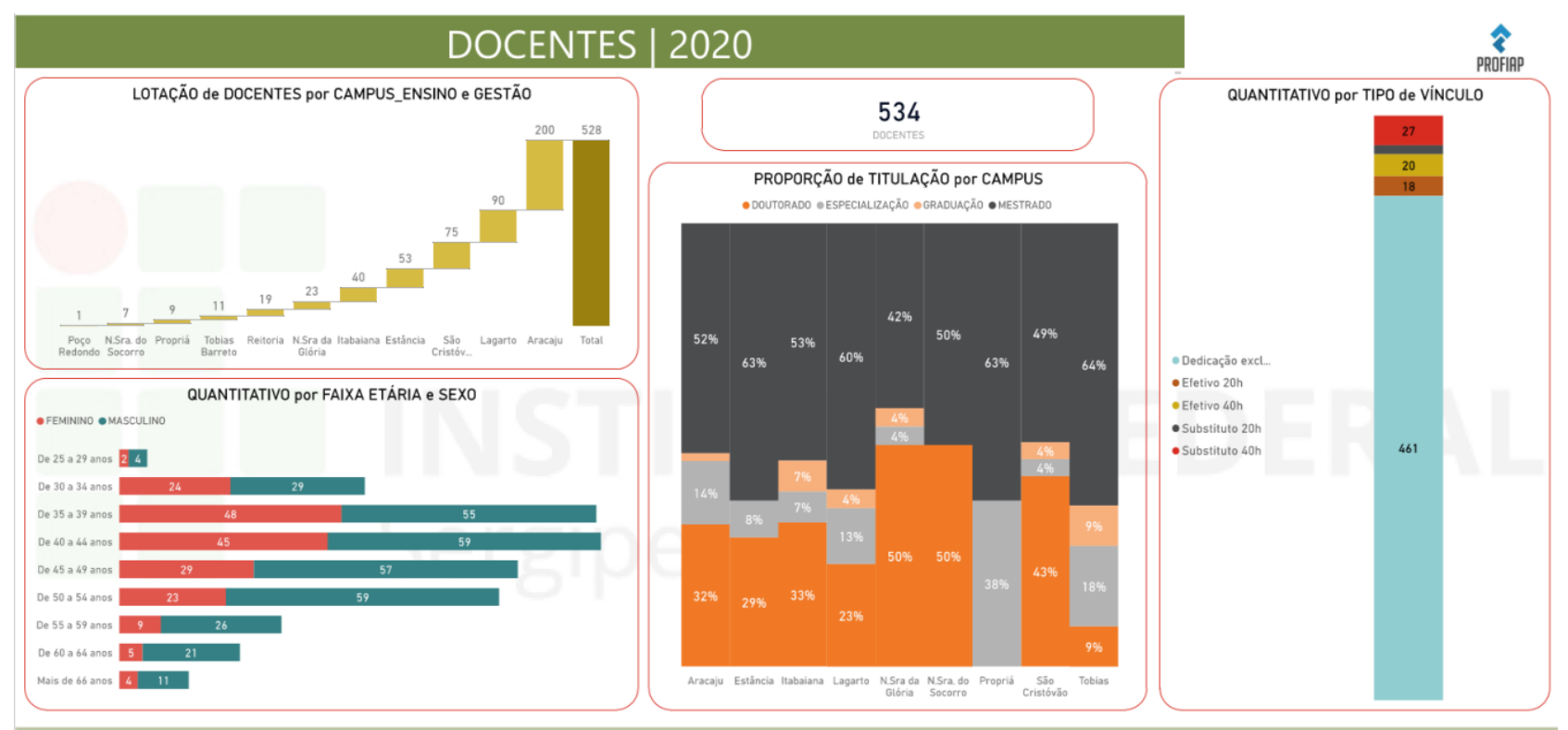

Fonte: elaborado pelos autores no Power BI Desktop, 2020. 
Figura 10 -

Dashboard 6: indicadores fixados pelo acórdão n. 2.267/2005/TCU.

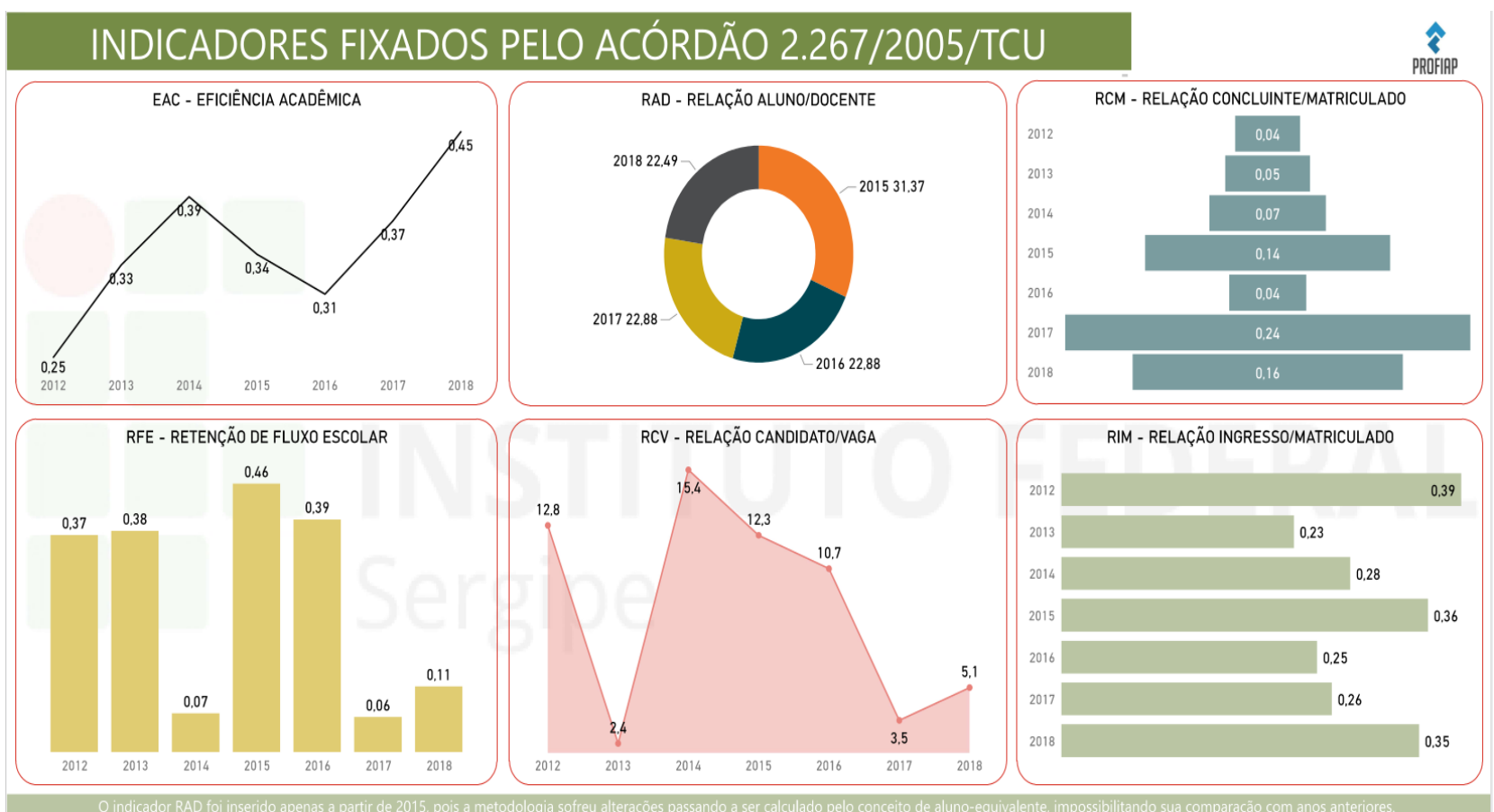

Fonte: elaborado pelos autores no Power BI Desktop, 2020.

Figura 11 -

Dashboard 7: indicadores regulamentados pela portaria n. 429/2020/MEC.

\section{INDICADORES REGULAMENTADOS PELA PORT.429/2020/MEC}

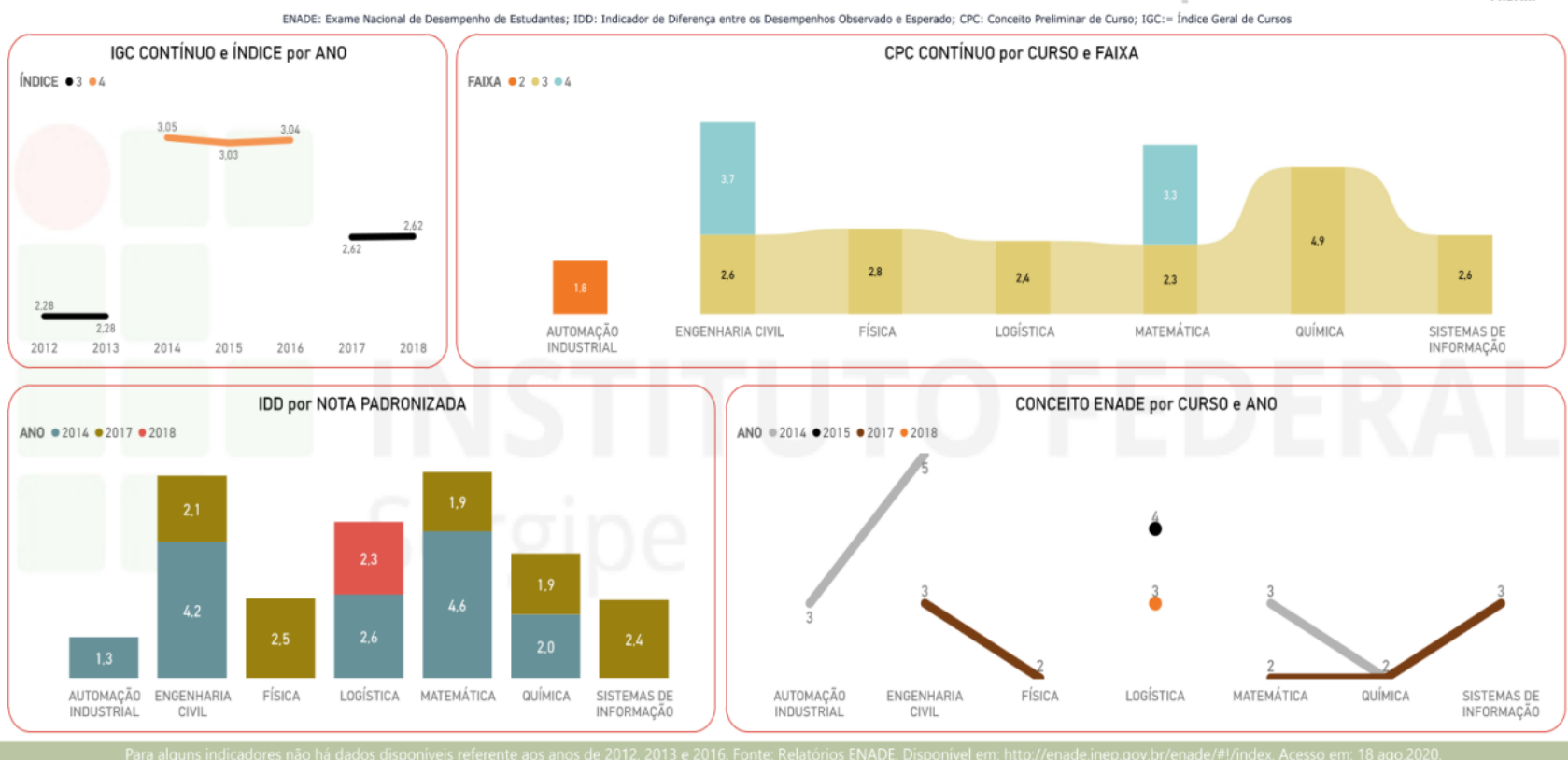

Fonte: elaborado pelos autores no Power BI Desktop, 2020. 
O Power BI oferece um sistema dinâmico em que é possível que o gestor escolha seus próprios filtros - curso, semestre, situação de matrícula, etc - e com informações em tempo real. $\mathrm{O}$ emprego do Power $\mathrm{BI}{ }^{\circledR}$ no IFS oferecerá, de forma fácil e rápida, uma leitura fiel sobre informações específicas ou contextos, se assim for a necessidade do gestor.

\section{Considerações finais}

O sucesso de uma organização pública é também resultado do grau de envolvimento da gestão. A sociedade tem acompanhado e exigido cada vez mais transparência na gestão de recursos, nos resultados e nos critérios utilizados para as decisões.

Quando instituições públicas propõem-se a adotar novas tecnologias da informação para diagnosticar, monitorar e avaliar passa-se da mera ação administrativa para exercer sua função precípua, que é a prestação de serviços à população. A gestão da informação aliada à transparência ativa e a modernização da gestão dos dados pode conferir bons resultados de gestão se utilizados com recursos adequados e propostos neste trabalho.

O principal objetivo desta pesquisa foi propor um sistema de informação de suporte à decisão para o IFS, construindo um painel de gestão acadêmica capaz de auxiliar os gestores no processo decisório e no acompanhamento e monitoramento dos resultados. Foi possível efetuar a aplicação prática do objeto de estudo, o que configurou a relação teórico-prática. A proposta de utilizar um sistema de suporte à decisão vem para atender uma fragilidade institucional, pois, o sistema utilizado atualmente carece de algumas funcionalidades, dinamismo e características que os artefatos de BI podem suprir.

O painel de gestão acadêmica é composto por informações importadas do Sigaa, voltadas especialmente para as vertentes de processo seletivo, perfil do aluno, concluintes, evasão e docentes. Nessas dimensões foi possível explorar e compor novas percepções para proporcionar conhecimento e amparar decisões e ações que forem oportunas à administração.

Além destes o painel de gestão também apresenta os principais indicadores estabelecidos pelo acórdão 2.267/2005/TCU e portaria 429/2020/MEC. Expostos por uma série histórica é possível perceber o compasso de cada um dos indicadores e, desta maneira, levar ao gestor uma informação útil e atualizada.

Como resultados dessa investigação, foi possível demonstrar que o modelo proposto de painel de gestão acadêmica tem potencial para subsidiar os gestores do IFS no processo decisório. $\mathrm{O}$ monitoramento dos principais indicadores acadêmicos promove a transparência ativa, gestão do conhecimento e melhor aproveitamento do banco de dados já existente. O uso do Power $\mathrm{BI}{ }^{\circledR}$ para acompanhamento e controle da gestão mostrou-se uma solução eficiente para a problemática apresentada, pois, possibilita análises flexíveis, intuitivas e rápidas.

\section{Referências}

ACKOFF, Russel. From data to wisdom. Journal of Applies Systems Analysis, New York, v. 16,1989 , p. 3-9. 
ANGELIS, Cristiano Trindade de. A model of knowledge management and organizational intelligence for public sector administrations. International Journal of Public Administration, São Paulo, 2013, p. 1-29.

BAKER, Ryan; ISOTANI, Seiji; CARVALHO, Adriana. Mineração de dados educacionais: oportunidades para o Brasil. Brazilian Journal of Computers in Education, Porto Alegre, v.19, n. 2, 2011, p. 3-13.

BARBIERI, Carlos. BI2 - Business intelligence: modelagem e qualidade. Rio de Janeiro: Elsevier. 2011.

BATISTA, Fábio Ferreira. Modelo de gestão do conhecimento para a administração pública brasileira: como implementar a gestão do conhecimento para produzir resultados em benefício do cidadão. Brasília: Ipea, 2012.

BEM, Roberta Moraes; PRADO Maria Lourde; DELFINO, Nelson. Desafios à implantação da gestão do conhecimento: a questão cultural nas organizações pública federais brasileiras. Revista Digital de Biblioteconomia e Ciência da Informação, Campinas, v. 11, n. 2, 2013, p. 123-135.

BERG, Bruce Laurence. Qualitative research methods for the social sciences. Massachusetts: Pearson, 2004.

BRASIL. Instituto Federal de Educação, Ciência e Tecnologia de Sergipe (IFS). Disponível em https://bit.ly/39eOp8e. Acesso em 25 jan. 2020.

BRASIL. Ministério da Educação. Brasília: MEC, 2020. Disponível em https://bit.ly/2H8Jlkq. Acesso em 22 jan. 2020.

CRESWELL, John W. Research desing: qualitative quantitative and mixed approaches. Thousand Oaks: Sage, 2014.

CUBILLO, Julio. La inteligencia empresarial en las pequeñas y medianas empresas competitivas de América Latina: algunas reflexiones. Ciência da Informação, Brasília, v. 26, n. 3, 1997, p. 235-242.

DALKIR, Kimiz. Knowledge Management in theory and practice. Cambridge: MIT Press, 2011.

DANIEL, Ben Kei. Big data and learning analytics in higher education: current theory and practice. Suiça: Springer, 2016.

FENAE. Empresas públicas: mitos e fatos 2019. Brasilía: Sest, 2020.

GOMES, Elisabeth; BRAGA, Fabiane. Inteligência competitiva em tempos de big data: analisando informações e identificando tendências em tempo real. Rio de Janeiro: Alta Books, 2017.

KOTU, Vijay; DESHPANDE, Bala. Predictive analytics and data mining. Amsterdam: Elsevier, 2015.

LAPA, Joaquim; BERNARDINO, Jorge; FIGUEIREDO, Ana. A comparative analysis of open source business intelligence platforms. ACM International Conference Proceeding Series, 2014, p. 86-92. Disponível em https://dl.acm.org/doi/10.1145/2618168.2618182. Acesso em 5 abr. 2010

LAGO, Karine; ALVES, Laennder. Dominando o power BI. São Paulo: DataB, 2018.

$\mathrm{LOH}$, Stanley. BI na era do big data para cientistas de dados: indo além de cubos e dashboards na busca pelos porquês, explicações a padrões. Porto Alegre: Stanley Loh, 2014. 
MAZZUCATO, Mariana. O Estado empreendedor: desmascarando o mito do setor público vs. setor privado. São Paulo: Portfolio-Penguin, 2014.

MELO, Douglas Arrais; FUCHIGAMI, Hélio Yochihiro. Proposta de índice bidimensional de transparência da informação público-eletrônica como ferramenta para participação e controle sociais. Revista Eletrônica de Administração, Porto Alegre, v. 25, n. 2, 2019, p. 179-214.

MENDES, Tania. Gestão do conhecimento da informação. Alesp - Ato n. 05/2005 da Mesa. Disponível em https://bit.ly/2PvF5W3. Acesso em 21 fev. 2020.

NONAKA, Ikujiro. A empresa criadora de conhecimento. Rio de Janeiro: Campus, 2000.

NONAKA, Ikujiro; TAKEUCHI, Hirotaka. Criação de conhecimento na empresa: como as empresas japonesas geram a dinâmica da inovação. Rio de Janeiro: Campus, 1997.

OLIVEIRA, Djalma de Pinho Rebouças. Sistemas de informações gerenciais: estratégicas, táticas, operacionais. São Paulo: Atlas, 2004.

PALUDO, Augusto Vicente. Administração pública: teoria e questões. Rio de Janeiro: Elsevier, 2010.

PARDO, Sebastián; CORONEL, Juan Enrique; BERTONE, Rodolfo; THOMAS, Pablo. Gestión del conocimiento: un enfoque aplicado en la administración pública. CONGRESO ARGENTINO DE CIENCIAS DE LA COMPUTACIÓN, 28, 2013. Buenos Aires: Redunci, 2013. Disponível em https://bit.ly/2120E2x. Acesso em 25 out. 2020.

PIAIA, Thami Covatti; CEZARO, Bárbara de. ZIEGLER, Jean. A. A proteção da cidadania no acesso à internet e à informação no Brasil. In: CERVI, Jackson Roberto; HAHN, Noli Bernardo (org.). Diálogo e entendimento: direito e multiculturalismo e políticas de cidadania e resolução de conflito. Campinas: Millennium, 2017, p.199- 215.

RODRIGUES, Charles; BLATTMANN, Ursula. Gestão da Informação e a importância do uso de fontes de informação para a geração do conhecimento. Perspectivas em Ciência da Informação, Belo Horizonte, v. 19, n. 3, 2014, p. 4-29.

ROMERO, Cristobal; VENTURA, Sebastian. Data mining in education. Wiley interdisciplinary reviews: data mining and knowledge discovery, 2013. Disponível em https://bit.ly/3hlFHZZ. Acesso em 22 jul. 2020.

SILVA, Rosane Leal da; $\mathrm{HOCH}$, Patrícia Adriani; RIGHI, Lucas Martins. Transparência pública e a atuação normativa do CNJ. Revista Direito GV, São Paulo, v. 9, n. 2, 2013, p. 489-514.

SILVA, Rafaela; SILVA, Fernando; GOMES, Carlos. O uso do Business Intelligence (BI) em sistema de apoio à tomada de decisão estratégica. GEINTEC - Gestão, Inovação e Tecnologia, Aracaju, v. 6, n. 1, 2016, p. 2780-2798.

SOBRAL, Felipe; PECl, Alketa. Administração: teoria e prática no contexto brasileiro. São Paulo: Prentice Hall, 2008.

TCE. Controle cidadão. Transparência na gestão pública. Fortaleza: TCE, 2017.

TORGO, Luís. Data mining with r learning with case studies. Boca Raton: CRC Press, 2017.

VALENTIM, Marta Lígia Pomim. Inteligência competitiva em organizações: dado, informação e conhecimento. DataGramaZero, Rio de Janeiro, v. 3, n. 4, 2002, p. 1-13.

VERGARA, Sylvia Constant. Projetos e relatórios de pesquisa em administração. São Paulo: Atlas, 2013. 
VESOLOSKI, Simone Paula; VESOLOSKI, Joseli Fátima; DEZORDI, Evandro Luis. A garantia ao acesso à informação e à transparência da administração pública frente ao direito do cidadão. Revista Perspectiva, Erechim, v. 44, n. 166, 2020, p. 75-86.

WITTEN, Ian H; FRANK, Elbe. Data mining: practical machine learning tools and techniques. Massachusetts: Morgan Kaufmann, 2005.

Baby de Fátima Barbosa Parisi é administradora no Instituto Federal de Sergipe.

Orcid: https://orcid.org/0000-0003-0015-0482.

Endereço: Avenida Jorge Amado, s/n - 49025330 - Aracaju - SE - Brasil.

E-mail: fatimaparisi@gmail.com.

Kleber Fernandes de Oliveira é professor associado na Universidade Federal de Sergipe.

Orcid: https://orcid.org/0000-0001-6568-6240.

Endereço: Avenida Marechal Rondon, s/n - 49100-000 - São Cristóvão - SE - Brasil.

E-mail: koliveira@academico.ufs.br.

Critérios de autoria: a concepção da ideia foi de Kleber Oliveira e a coleta, descrição, análise e construção do documento foi de Baby Parisi. Os autores discutiram os resultados e contribuíram para a versão final do manuscrito.

Recebido em 4 de novembro de 2020.

Aceito em 7 de maio de 2021.

(2) $\oplus \Theta \Theta$ 